\title{
Leptin Controls Bone Formation Through a Hypothalamic Relay
}

\author{
GERARD KaRSENTY \\ Baylor College of Medicine, One Baylor Plaza, Houston, Texas 77030
}

\begin{abstract}
$\Lambda \mathrm{BSTR} \wedge \mathrm{CT}$
Menopause favors osteoporosis and obesity protects from it. In an attempt to decipher the molecular bases of these two well-known clinical observations, we hypothesized that they meant that bone remodeling, body weight, and reproduction are controlled by identical endocrine pathways. We used mouse genetics as a tool to translate these clinical observations into a molecular hypothesis. The $\mathrm{ob} / \mathrm{ob}$ and $\mathrm{db} / \mathrm{db}$ mice were valuable models, since two of the three functions thought to be co-regulated are affected in these mice: they are obese and hypogonadic. Surprisingly, given their hypogonadism, both mouse mutant strains have a high bone mass phenotype. Subsequent analysis of the mechanism leading to this high bone mass revealed that it was due to an increase of bone formation. All data collected indicate that, in vivo, leptin does not act directly on osteoblasts but rather through a central pathway following binding to its specific receptors located on hypothalamic nuclei. This result revealed that bone remodeling, like most other homeostatic functions, is under hypothalamic control. The nature of the signal downstream of the hypothalamus is unknown but current experiments are attempting to identify it.
\end{abstract}

\section{Use of Mouse Genetics in Physiologic Studies}

When homologous recombination in embryonic stem (ES) cells made its entry on the scene of biology, it was heralded, and rightly so, as a breakthrough of historical importance in developmental biology (Capecchi, 1989). It allowed one to study the function of any given gene in vivo by simply deleting it from the mouse genome, thereby giving to mouse genetics the power of yeast, worm, or fly genetics. This was only 10 or 12 years ago, so we have just begun to accept the revolutionary notion that genes important for worm or fruit fly development also may be important during higher organism development. We knew very little about the genetic control of early or even late vertebrate development; the power of this technology to decipher vertebrate embryology seemed limitless. Moreover, it was as a given that what is learned in mice will apply to other vertebrates, including humans. As a matter of fact, the many instances where a mutation of the same gene in mice and in humans led to the same phenotypic consequences demonstrated that this assumption was true overall. For all of these reasons, 
gene-deletion technology was received with an extraordinary enthusiasm as a means to understand mouse, and thereby human, embryology. Retrospectively, it is hard to recount the euphoria surrounding the early success of gene-deletion technology at the beginning of the 1990s.

With time, the technique became even more sophisticated. It is, for instance, now possible to delete genes at a specific time and/or in a specific cell type. Moreover, with the progress on mouse genome mapping, it has become increasingly easier to clone the genes mutated in spontaneously occurring mutations. This approach has contributed significantly to the success of mouse genetics. Yet, with time, the fascination for gene-targeting technology and, more generally, for the power of mouse genetics to study questions relevant to all mammals has partly dissipated. Overall, it has lost most of its magical right of a priori approval.

Yet, mouse genetics is much more powerful and useful that it was a decade ago. With all the technical improvement mentioned above, it is possible to study more than embryologic development. One can, for instance, analyze the molecular bases of tumor formation (Kumar et al., 1995), a rather poorly understood field, or areas of vertebrate physiology for which there are more beliefs than data (Carmeliet et al., 1998; Kappel et al., 1994). In particular, in these latter areas, the use of mouse genetics may potentially revolutionize our understanding of the physiopathology and possibly the management of degenerative diseases. This new - and, so far, only - way to explore untested questions should be welcomed with the same enthusiasm as the one manifested by developmental biologists 10 years ago. Indeed, what is at stake is at least of the same biologic importance and possibly of more-immediate impact therapeutically. But for that to happen, one has to take mouse genetics at face value. If a gene deletion gives a clear phenotypic abnormality that is rigorously studied, it should be accepted. Especially if it challenges previous beliefs, it should be exploited to reanalyze our view of a physiologic process.

This statement may sound a bit defensive and rightly so. It is defensive because, when it comes to physiology, mouse genetics faces several obstacles, even though its potential usefulness is tremendous. One of these obstacles is that phenotypic abnormalities may be subtle and hard to uncover. Another one, possibly harder to overcome, is that it may contradict some untested textbook assumptions. Nevertheless, mouse genetics is in physiology what it is in developmental biology: the best-available approach to study the biologic function of a given gene, in a given cell type, at a given time. This is the assumption that supports the various projects summarized in this chapter.

\section{Bone Remodeling as a Complex Function}

In humans, and in vertebrates in general, bone mass is maintained constant between the end of the period of linear skeletal growth and gonadal failure by a 
complex and dynamic process termed bone remodeling (Karsenty, 1999). Initially, there is resorption of pre-existing bone by a bone-specific cell type, the osteoclast. This is a relatively rapid step that occurs in a few weeks. It is followed by de novo bone formation through another bone-specific cell type, the osteoblast. This latter step is slower and may take several months, so that a typical cycle of bone remodeling requires at least 3 months. This continuous destruction/formation cycle occurs in multiple locations at the same time in such a way that the bone mass of a given individual remains constant until late in life. In women, bone mass remains constant until menopause, when the sex steroid deprivation characterizing this life stage leads to a relative increase in bone resorption over bone formation, decreased bone mass (osteopenia), and possible risk of fractures after a minimum traumatism (osteoporosis) (Karsenty, 1999). The biologic importance of bone remodeling is illustrated by the fact that osteoporosis is the most-frequent degenerative disease in developed countries, affecting 28 million people in the United States alone. Moreover, its incidence will only increase with overall aging of the population.

The fact that bone remodeling occurs in multiple locations at the same time has long been viewed as a suggestive argument in favor of a local, autocrine and/or paracrine regulation (Manolagas, 2000). There are several experimental reasons to believe that this type of regulation must exist. One of them, and not the least persuasive, is that differentiation of osteoclasts, the bone-resorbing cells, has been shown to depend on the presence of genes expressed in the osteoblasts, the bone-forming cells. For instance, genetic experiments in mice have shown that osteoprotegerin (OPG), a soluble TNF receptor present in the bone extracellular matrix, inhibits osteoclast differentiation. However, OPG ligand, a growth factor also present in the bone micro-environment, favors bone resorption (Bucay et al., 1998; Kong et al., 1999; Lacey et al., 1998; Simonet et al., 1997). To a certain extent, another cytokine, interleukin-6 (IL-6), is involved in controlling bone resorption (Poli et al., 1994). It is likely that other secreted molecules will be demonstrated to contribute to this type of regulation of bone remodeling.

The same observation that bone remodeling occurs in multiple locations at the same time can be taken as a suggestive argument in favor of an endocrine regulation of bone remodeling. Such regulation should not be surprising, as most homeostatic functions of the body are under endocrine regulation, superimposed on local regulation. Here, also, the evidence for this type of regulation is overwhelming. As mentioned earlier, sex steroid hormones play a critical role in controlling tightly osteoclast differentiation and bone resorption (Couse and Korach, 1999). We do not understand fully their mechanisms of action but it is clear that gonadal failure in females and, to a certain extent, in males favors bone resorption in humans, rats, and, to a lesser extent, mice. Other hormones favor bone resorption physiologically: parathyroid hormone (PTH), whose mechanism of action in bone is still poorly understood (Potts and Juppner, 1998), and calci- 
tonin that has receptors on the osteoclasts (Nicholson et al., 1986). The endocrine control of bone resorption by already-differentiated osteoclasts plays a crucial role and does not exclude that local factors could contribute or amplify the resorptive action of hormones. It is important from the beginning to emphasize that these two types of regulation, local and endocrine, are not exclusive and can, in fact, be synergistic.

\section{Control of Bone Formation Is Poorly Understood}

All the regulatory events described above, regardless of their nature, affect the bone-resorption aspect of bone remodeling, thus pointing out a blatant lack of knowledge about the molecular control of bone formation by osteoblasts. The only molecule known to affect the rate of bone formation by the osteoblast is a transcription factor, Cbfal (Ducy et al., 1999). Intuitively, however, it seems reasonable that the same type of regulations that apply to bone resorption, local and endocrine, also must apply to bone formation. One experiment from our laboratory suggested even more strongly that there was a tight and critical endocrine regulation of bone formation. Curiously, the most-important meaning of this experiment escaped us initially. We generated transgenic mice expressing the thymidine kinase ( $t k$ ) gene specifically in differentiated osteoblasts, the only cells that synthesize the bone matrix (Corral et al., 1998). The product of this gene is innocuous until cells expressing $t k$ are treated with gancyclovir. This leads to a disruption of DNA replication in the $t k$-expressing cells and to cell death. This cell-ablation process is reversible at the arrest of the gancyclovir treatment.

In absence of any detectable bone formation, bone resorption continued unaffected in these $o s c-t k$ (osteocalcin promoter driving $t k$ expression) mice. As a result, their bones were empty and osc-tk mice stopped growing, as osteoblasts are required for longitudinal growth of the skeleton. Surprisingly, after the gancyclovir treatment was stopped, within a month (a very short period of time according to bone-remodeling standards), the bones of the transgenic mice had recovered a normal appearance and the $o s c-t k$ mice reached a normal size. What was most remarkable in this recovery was its extreme precision. The osc-tk transgenic mice regained a normal bone volume, neither less nor more than their wild-type mice littermates. This extreme precision in the recovery process, together with its speed, suggested that differentiated osteoblasts were able to sense how much bone matrix should be synthesized in different circumstances and that they had at least two speeds to synthesize the bone matrix. Indeed, osteoblasts could, for several days after gancyclovir withdrawal, synthesize large amounts of bone matrix to repopulate the bones. Then, when the bone volume had reached the level observed in wild-type mice, the osteoblasts of the osc-tk mice seemed able to decrease the amount of bone matrix deposited so that bone volume remained normal. We interpreted this ability of the osteoblasts to sense the need of protein synthesis as 
an indication of the existence of endocrine control of bone formation. This led us to search for putative hormones regulating osteoblast function under physiological circumstances.

\section{Evidence for a Common Control of Bone Mass, Body Weight, and Reproduction}

In an effort to identify circulating molecules that could regulate bone formation, we decided to use the clinical literature as a tool to identify one endocrine pathway. As mentioned earlier, the most-frequent bone-remodeling disease is osteoporosis, which is characterized by a relative increase of bone resorption over bone formation. Among the multitude of clinical features characterizing osteoporosis, we were struck by two of them: 1) gonadal failure favors bone loss and 2) obesity protects from bone loss, even after menopause (Felson et al., 1993; Raven et al., 1999; Riggs and Khosla, 1998; Riggs and Melton, 1986; Tremollieres et al., 1993). We hypothesized that the fact that bone mass was affected by a gonadal function and body weight controls bone mass was an indication that these three homeostatic functions - bone mass, body weight, and reproduction - were under the control of the same hormone(s). Given the recent progress in our molecular understanding of the control of appetite and body weight, this hypothesis could be tested in vivo. One has to be aware, however, that this hypothesis has one implication that should be accepted a priori, if one decides to test it. The control of both body weight and reproduction is primarily, although not exclusively, of neuroendocrine nature (i.e., it relies on hormones acting through, or secreted by, the hypothalamus). Therefore, it was a distinct possibility that this investigation might uncover a neuro(endo)crine regulation of bone remodeling and, more specifically, of bone formation.

\section{Leptin as One Regulator of Bone Formation}

In the hypothetical framework of a common regulation for bone mass, body weight, and reproduction, leptin was certainly an attractive - although not the only - candidate molecule (Friedman and Halaas, 1998; Spiegelman and Flier, 1996). Indeed, in mice, rats, and human beings deficient in leptin or its receptor, two of the functions allegedly co-regulated in this model are affected: these animals or patients are obese and hypogonadic (Chen et al., 1996; Clement et al., 1998; Lee et al., 1996; Montague et al., 1997; Strobel et al., 1998; Tartaglia et al., 1995; Zhang et al., 1994). Before going further in describing leptin's action on bone, it is important to emphasize that no animal model has been described in which there is a co-existence of hypogonadism and high bone mass.

The expectations were that the existence of a hypogonadism in these two mutant mouse strains should lead to a low bone mass phenotype whose severity 
may or may not be limited by obesity. Thus, it was a complete surprise to notice that these mice had a high bone mass phenotype (Ducy et al., 2000). The phenotypic changes were so important that they could be detected with a low-sensitivity technique such as x-ray. Obviously, these phenotypic changes were subsequently confirmed by histologic analysis. The phenotypic abnormalities affected the entire skeleton, including long bones, vertebrae, and the skull, as one would expect from an endocrine effect. The initial groups of mice that were analyzed were 6 months old with a full-blown obesity, raising the question whether this phenotypic abnormality was secondary to the obesity. To address this concern, we used ob/ob mice that were put on a low-fat diet at birth. This regimen can postpone the appearance of the obesity in these mice until the sixth week of life. At 4 weeks of age, these ob/ob mice had a normal weight but already a high bone mass phenotype, albeit less severe than the one observed in adult ob/ob animals. This phenotype seemed specific to the leptin signaling pathway, as it could not be observed in Agouti yellow mice. Agouti yellow mice are another mutant strain that develops an obesity phenotype, secondary to the binding of the Agouti protein to the melanocortin receptor 4 (MC-R4) in the hypothalamus (Dinulescu and Cone, 2000). The Agouti protein acts as an antagonist of MC-R4 signal transduction (Lu et al., 1994). Neither in this Agouti yellow mouse model nor in wild-type mice fed a high-fat, high-carbohydrate diet for 1 month to achieve obesity a high bone mass was observed.

There are three possible mechanisms to achieve a high bone mass phenotype. The first is to have an increase in bone formation itself secondary to an increase in osteoblast differentiation and/or function. The second is to have a partial failure of bone resorption. The third possible mechanism is a combination of these two. To study bone formation dynamically, one can rely on histomorphometry, a technique based on the fact that calcein will bind at the front of mineralization in bone. Thus, when injected 8 days apart, calcein allows one to measure the mineral apposition rate, the rate of bone formation, and other parameters (Parfitt $e t$ al., 1987). Using this technique, we could demonstrate that there was a clear increase in all the parameters of bone formation in ob/ob and $\mathrm{db} / \mathrm{db}$ mice prior to the appearance of obesity but not in any of our control animals. All the parameters of bone formation were increased, except an important one. There was a normal number of osteoblasts in ob/ob and db/db mice, demonstrating that leptin does not affect osteoblast proliferation but only their function. This is important because, if one considers using an antagonist of the leptin pathway to favor bone formation, this absence of a mitogenic function is certainly a great advantage.

To study the bone-resorption aspect of bone remodeling in mice deprived of leptin signaling, we took advantage of their hypogonadism. Hypogonadism always leads to an increase in osteoclast numbers (Marcus et al., 1996) and this rule holds true in ob/ob and $\mathrm{db} / \mathrm{db}$ mice as well. Thus, we reasoned that if the osteoclasts of these mice were defective, correcting their hypogonadism would decrease 
their osteoclast numbers but not worsen their phenotype. If, on the other hand, the osteoclasts of the ob/ob and $\mathrm{db} / \mathrm{db}$ mice were working normally, correcting the hypogonadism of these mice should worsen their bone phenotype by decreasing their osteoclast numbers. To test which of these two models was correct, we treated male and female ob/ob mice with testosterone or estradiol implants, respectively, for 4 months. This treatment corrected their hypogonadism and decreased the number of osteoclasts in these mice but also worsened considerably their high bone mass phenotype. These results demonstrated, along with other cell-based, in vitro assays, that leptin did not act on bone resorption. At that stage, regardless of the mechanism of action of leptin, this high bone mass phenotype was quite extraordinary, since it occurred in hypogonadal mice. The uniqueness of the coexistence of high bone mass and hypogonadism required us to identify one general mechanism of action of leptin in the control of bone formation.

\section{High Bone Mass Phenotype Observed in Absence of Leptin Signaling Is Dominant}

Although the high bone mass phenotype precedes the appearance of obesity, it is still conceivable that it is secondary to the existence of other endocrine abnormalities in the ob/ob and $\mathrm{db} / \mathrm{db}$ mice. This possibility is, theoretically at least, rather unlikely, as no hormones are known to favor bone formation to the extent observed in eugonadal ob/ob mice. Nevertheless, it was tested thoroughly. Most of the endocrine abnormalities characterizing $\mathrm{ob} / \mathrm{ob}$ and $\mathrm{db} / \mathrm{db}$ mice should have, at best, marginal effects on bone formation or bone resorption. The exception is that these mice are hypercortisolic, a condition that favors a decrease, not an increase, in bone formation (Ahima et al., 1996; Reid, 1997).

But there is a more-convincing and more-important argument to exclude any endocrine dysregulation at the origin of this phenotype. This argument is that the high bone mass phenotype can be observed in $\mathrm{ob} /+$ and $\mathrm{db} /+$ animals that not only are not obese but also have none of the known endocrine abnormalities observed in the ob/ob and db/db animals. This latter aspect of the bone phenotype observed in the absence of leptin has considerable therapeutic potential, as it implies that one could modulate the leptin pathway to affect bone mass without affecting body weight. This dominant effect also indicates that bone is a major target organ of leptin, as there are very few examples of hormones whose partial deficiency causes such a dramatic phenotype.

\section{Absence of Evidence for a Local or Endocrine Effect of Leptin on Osteoblasts in Vivo}

If the high bone mass phenotype observed in absence of leptin signaling is not secondary to the obesity or any endocrine abnormalities, then how does it 
develop? As for every secreted molecule, leptin could signal to the osteoblasts through three possible and not necessarily exclusive pathways. It could act locally through an autocrine/paracrine mechanism, it could act through a classical endocrine pathway, and, finally, it could act - as it does for the control of appetite - through a neuro(endo)crine pathway. The point here was not so much to push one mode of action and to exclude the others a priori but rather to analyze, in the most-neutral way, the abnormalities of the ob/ob and db/db mice and to take full advantage of what mouse genetics can teach us, especially if it opens new directions for research and establishes new concepts of physiology.

Because the absence of leptin does not affect the osteoblast number, one has to assume that, regardless of the mechanism involved, leptin affects the function of the osteoblast. Therefore, all experiments aimed at demonstrating an autocrine, paracrine, or endocrine effect of leptin should be conducted using differentiated osteoblasts (i.e., cells able to synthesize and deposit a bone matrix). By definition, an autocrine regulation requires that leptin is expressed in osteoblasts. Northern hybridization failed to detect any leptin mRNA expression in bone or primary cultures of osteoblasts, even after a long exposure, thus excluding the possibility of an autocrine mechanism of action as leptin's main mode of action on bone formation. A paracrine or endocrine mechanism of action has the same requirement: differentiated osteoblasts must have signal-transducing leptin receptors on their surface. There are multiple isoforms of the leptin receptor but one only, ObRb, has been shown to have signal-transduction ability (Chen et al., 1996; Lee et al., 1996). ObRb is expressed predominantly in four nuclei of the hypothalamus. We could not detect any expression of ObRb in primary osteoblast cultures. This result was in contradiction to the result of Thomas and coworkers (1999) using transformed cells; moreover, it was based on a reverse transcription-polymerase chain reaction (RT-PCR) analysis. For these two reasons, we felt that more-reliable assays of a biochemical, genetic, and physiologic nature were needed to establish this important point in vivo.

Signal transduction through ObRb leads to phosphorylation of Stat 3, a transcription factor, and increased expression of early genes such as Tis 11 and C-fos (Baumann et al., 1996; Elmquist et al., 1997; Ghilardi et al., 1996; Moitra et al., 1998; Vaisse et al., 1996). One cytokine, oncostatin M, has a receptor that belongs to the same superfamily as the leptin receptor. Binding of oncostatin M to this receptor leads to phosphorylation of Stat 3 and early-response gene expression (Ahn et al., 1998; Levy et al., 1996). Moreover, oncostatin M receptors are present and abundant on the surface of differentiated osteoblasts (Bellido et al., 1996). Thus, to determine whether there were signal-transducing leptin receptors on osteoblasts, we used primary cultures of wild-type mouse osteoblasts that were treated with vehicle, various amounts of leptin, or with oncostatin $M$. While oncostatin M invariably induces Stat 3 phosphorylation and Tis 11 and $C$-fos expression, various doses of leptin, ranging from 8 to $100 \mathrm{ng} / \mathrm{ml}$, failed to induce 
any phosphorylation of Stat 3 or to affect Tis 11 and $C_{-f}$ fos expression. A genetic argument also supports the notion that the osteoblasts are not the direct target of leptin. One can assume that if the bone phenotype of the ob/ob and $\mathrm{db} / \mathrm{db}$ mice was due primarily to the absence of signal-transducing leptin receptors on the surface of differentiated osteoblasts, then primary osteoblast cultures of $\mathrm{db} / \mathrm{db}$ mice, which have an inactivating mutation in ObRb, should produce more bone matrix than primary osteoblast cultures of wild-type mice. This was not the case, demonstrating that, at least in culture, the absence of ObRb on osteoblasts does not cause any increase in bone formation. Taken together, all these evidences if they do not formally prove, because of their negative nature, that there is no leptin-signaling receptor on differentiated osteoblasts - strongly suggested that we should look elsewhere for a mechanism of action of leptin on bone formation. In any case, one additional piece of evidence, this time of a positive nature (see below), indicates that leptin can control bone formation without interacting physically with osteoblasts.

The observation that leptin signaling controls bone mass was made in mutant animals; therefore, it could be some type of genetic artifact. Indeed, it was possible that the absence of leptin signaling somehow allowed the adipocytes to secrete a molecule that they normally do not secrete and whose function is to favor bone matrix deposition by differentiated osteoblasts. To test this hypothesis, we used another mouse model, the "fat-free" mice (Moitra et al., 1998). These transgenic mice express a dominant-negative form of the leucine zipper family of transcription factors in their adipocytes (Ahn et al., 1998). Among the leucine zipper type of transcription factors expressed in adipocytes are the CCAAT/enhancer binding proteins (C/EBP), which play a critical role during adipocyte differentiation (Bellido $e t$ al., 1996). As a result, these mice have no adipocytes, no white fat, and a 20-fold reduction in leptin level (Ahn et al,, 1998). If the adipocytes, and not the absence of leptin signaling, are the cause for the high bone mass phenotype observed in ob/ob and $\mathrm{db} / \mathrm{db}$ mice, then these fat-free mice should have a normal bone mass. If, on the other hand, it is the decrease or absence of leptin expression that causes the phenotype, regardless of the number of adipocytes, then fat-free mice should have the same high bone mass phenotype as the ob/ob or ob/+mice. This was precisely the case, indicating that it is the absence of leptin signaling that is causing the phenotype, not the adipocytes. The fat-free mice are very important for another reason. They are an animal model of a human disease, generalized lypodistrophy, that is characterized, among many other features, by the existence of a high bone mass phenotype (Westvik, 1996).

\section{Leptin Acts Centrally to Control Bone Formation in Vivo}

The next general mechanism to study was the central or neuroendocrine control of bone formation. This was a valid pathway to test, since leptin is believed 
to control appetite, body weight, and the onset of puberty, primarily through its binding to specific receptors localized in four nuclei of the hypothalamus. For this pathway to be the one regulating bone mass, two criteria should be met; one genetic, one physiologic. First, intracerebroventricular (icv) infusion of leptin at a dose that does not cross the blood-brain barrier should correct the high bone mass phenotype of the ob/ob mice. Second, the same icv infusion of leptin, this time in wild-type mice, should lead to osteopenia.

When delivering a small amount of leptin (i.e., $8 \mathrm{ng} / \mathrm{h}$ ) through icv infusion in ob/ob mice, we noticed, as has been shown before, that these mice lost considerable weight. The dose of leptin used for icv infusion is the same that was used to demonstrate that leptin acts centrally to control body weight (Halaas et al., 1997). We made sure that there was no detectable leptin in the serum of these animals. This icv treatment lasted 1 month, a long time in terms of body weight control but a relatively short time in terms of bone remodeling, as a cycle of bone remodeling may last more than 3 months. Yet, at the end of this 1 -month period, the ob/ob animals treated with leptin had lost a considerable amount of bone mass, to the point that it was slightly lower than in all of the wild-type animals. This experiment demonstrated that leptin can affect bone formation without being present in the serum and therefore in the bone microenvironment. This positive result, along with the absence of signaling leptin receptor in primary osteoblast cultures, uncovered a novel level of regulation of bone remodeling through a central control.

As mentioned above, for this pathway to be of physiological relevance, one has to demonstrate that this type of regulation occurs not only in genetically modified animals but also in normal ones. As predicted, icv infusion of the same low dose of leptin in wild-type mice for 1 month led to the appearance of osteopenia in these animals and demonstrated the physiologic relevance of leptin's regulation of bone remodeling (Ducy et al., 2000).

No clear and simple model exists to explain how leptin controls appetite following its binding to ObRb in the hypothalamus (Elmquist et al., 1999; Marsh et al., 1999). Clearly, the mode of action of leptin on bone formation is not more advanced. However, one can attempt to take advantage of the current knowledge about the molecular control of appetite to address an initial question: is the leptin action affected by the same neuropeptides involved in the control of appetite/body weight and of bone mass? Neuropeptide Y (NPY) is one of the many neuropeptides that favor appetite and body weight gain. NPY expression is increased in ob/ob mice; NPY deficiency partially corrects the obesity phenotype of the ob/ob mice (Erickson et al., 1996; Schwartz et al., 1998). Thus, in terms of body weight and appetite control, leptin and NPY appear to have antagonistic functions. Nevertheless, icv infusion of NPY in wild-type mice caused a bone loss, indicating that leptin and NPY do not antagonize each other's function in the control of bone 
formation. This result may be viewed as an indication that leptin uses different sets of mediators to control body weight and bone mass.

\section{Neuroendocrine Regulation of Bone Mass Is Limited Neither to Mice nor to Leptin}

The entire study originally reported was performed in ob/ob and $\mathrm{db} / \mathrm{db}$ mice that are deficient in leptin or its receptor, respectively. It has subsequently been expanded to rats, with essentially identical results. This study was obviously not performed in humans for several reasons. First of all, the number of patients is too small. Second, ethical considerations will prevent anyone from performing invasive manipulations such as bone biopsies in these patients. Third, and not any less important, we have shown that the bone phenotype caused by the absence of leptin signaling worsens over time and is quite severe in adult animals. Human patients are children that were treated before the putative bone phenotype may have fully developed. Nevertheless, patients affected by generalized lypodistrophy (i.e., absence of adipocytes) have accelerated bone growth and high bone mass. Moreover, the recent demonstration that children deficient in MC-R4 are not only obese but also have a high bone mass gives further credence to the concept that body weight, bone mass, and reproduction share common neuroendocrine regulators (Farooqi et al., 2000). This latter result in humans is not in contradiction with our own observation that Agouti yellow mice, a mouse model of late obesity due to the binding of an antagonist protein to the MC-R4, had no bone abnormalities. Indeed, it is known that MC-R4 mutation causes a more-severe phenotype than the one observed in Agouti yellow mice (Huszar et al., 1997).

\section{Implications}

The finding that leptin regulates the bone formation arm of bone remodeling has important implications for leptin biology as well as for bone biology. The fact that $\mathrm{ob} /+$ and $\mathrm{db} /+$ mice already have a high bone mass phenotype is rather exceptional as, in most cases, hormone deficiencies do not have dominant phenotypes. This, together with our failure to demonstrate a peripheral action of leptin on osteoblasts, has several implications that can be tested experimentally. One implication is that if the apparent lack of effect of leptin on osteoblasts is true, then raising the serum concentrations of leptin should induce a state of leptin resistance but should not lead to osteoporosis. Another implication of the apparent predilection of leptin for bone could be that repcating the infusion of leptin with a lower dose should result in bone loss at doses that cannot affect body weight. A third and more-important implication of the dominant nature of the leptin function on bone formation is that it would be feasible to antagonize only partially the leptin signaling pathway, so that animals would have a higher bone mass 
without becoming obese or sterile. Finally, if leptin uses different pathways to control body weight and bone formation, then in animal models of obesity with leptin resistance, it may still be possible to induce bone loss through icv infusion of leptin.

In terms of bone biology, the implications are tremendous. Not only do these findings in mice, rats, and humans establish a new physiologic concept and provide a molecular basis for the well-known protective effect exerted by obesity on bone mass, they also open new directions of physiologic and pharmacologic research. One should first wonder, why do vertebrates need such a powerful brake to be applied on bone formation? This is a very speculative question. Although the consequences of an incorrect control of bone remodeling are not as immediately apparent as the consequences of an incorrect control of body weight, onc could argue that it is a critical function to regulate tightly during evolution. We already know that abnormalities in the regulation of bone resorption may result in osteopetrosis, a disease lethal during early childhood. Likewise, an uncontrolled increase in bone formation results in a massive increase in bone mass, a failure of bone marrow to maintain a normal hematopoiesis, and possibly a drop in serum calcium concentration, all abnormalities that lead to early death (Jochum et al., 2000). If regulating bone formation is so important, then it is likely that leptin is not the only regulator and a positive regulation of bone formation probably exists to counteract leptin's function. Likewise, if one adopts a unifying view of bone remodeling, then it is conceivable and testable that the bone-resorption arm of bone remodeling may be under central hormonal regulation.

Finally, it is still too early to determine whether this novel regulation of bone remodeling will result in novel therapeutic approaches but at least this a reasonable route to explore. As mentioned throughout this review, three aspects of leptin regulation of bone mass are particularly attractive in that regard. The first aspect is that modulating the leptin signaling pathway offers the possibility to increase bone formation that is defective in osteoporosis. Conceivably, a treatment that would increase bone formation could be viewed as a cure, if not a preventive treatment, for osteoporosis. The second aspect is that, in absence of leptin signaling, there is an increase in bone formation without any increase in osteoblast numbers. In other words, there is no mitogenic effect of the absence of leptin signaling on the osteoblast, which is always an advantage if one thinks of a long-term drug treatment. The final aspect is that the bone phenotype of the leptin-deficient mice is dominant, whereas the obesity is recessive, thus raising the possibility that partial inhibitors of leptin action may have beneficial and selective effects on bone mass. 


\section{ACKNOWLEDGMENTS}

The author is grateful to Drs. T. Schinke and P. Ducy for critical reading of the manuscript. This work was supported by National Institutes of Health R01 R01 DK58883.

\section{REFERENCES}

Ahima, R.S., Prabakaran, D., Mantzoros, C., Qu, D., Lowell, B., Maratos-Flier, E., and Flier, J.S. (1996). Nature 382, 250-252.

Ahn, S., Olive, M., Aggarwal, S., Krylov, D., Ginty, D.D., and Vinson, C. (1998). Mol. Cell. Biol. 18, 967-977.

Baumann, H., Morella, K.K., White, D.W., Dembski, M., Bailon, P.S., Kim, H., Lai, C.F., and Tartaglia, L.A. (1996). Proc. Natl. Acad. Sci. U.S.A. 93, 8374-8375.

Bellido, T., Stahl, N., Farruggella, T.J., Borba, V., Yancopoulos, G.D., and Manolagas, S.C. (1996). J. Clin. Invest. 2, 431-437.

Bucay, N., Sarosi, I., Dunstan, C.R., Morony, S., Tarpley, J., Capparelli, C., Scully, S., Tan, H.L., Xu, W., I acey, D. L., Royle, W.J., and Simonet, W.S. (1998). Genes Devel. 12, 1260-1268.

Capecchi, M.R. (1989). Science 4910, 1288-1292.

Carmeliet, P., Moons, L., and Collen, D. (1998). Cardiovasc. Res. 1, 8-33.

Chen, H., Charlat, O., Tartaglia, L.A., Woolf, E.A., Weng, X., Ellis, S.J., Lakey, N.D., Culpepper, J., Moore, K.J., Breitbart, K.E., Duyk, G.M., Tepper, R.I., and Morgenstern, J.P. (1996). Cell 84, 491-495.

Clement, K., Vaisse, C., Lahlou, N., Cabro, S., Pelloux, V., Cassuto, D., Gourmelen, M., Dina, C., Chambaz, J., Lacorte, J.M., Basdevant, A., Bougneres, P., Lebouc, Y., Froguel, P., and Guy-Grand, B. (1998). Nature 6674, 398-401.

Corral, D.A., Amling, M., Priemel, M., Loyer, E., Fuchs, S., Ducy, P., Baron, R., and Karsenty, G. (1998). Proc. Natl. Acad. Sci. U.S.A. 95, 13835-13840.

Couse, J.F., and Korach, K.S. (1999). Endocr. Rev. 3, 358-417.

Dinulescu, D.M., and Cone, R.D. (2000). J. Biol. Chem. 275, 6695-6698.

Ducy, P., Starbuck, M., Priemel, M., Shen, J., Pinero, G., Geoffroy, V., Amling, M., and Karsenty, G. (1999). Genes Devel. 13, 1025-1036.

Ducy, P., Amling, M., Takeda, S., Priemel, M., Schilling, A.F., Beil, F.T., Shen, J., Vinson, C., Rueger, J.M., and Karsenty, G. (2000). Cell 2, 197-207.

Elmquist, J.K., Ahima, R.S., Maratos-Flier, E., Flier, J.S., and Saper, C.B. (1997). Endocrinology 138, 839-842.

Elmquist, J.K., Elias, C.F., and Saper, C.B. (1999). Neuron 2, $221-232$.

Erickson, J.E., Hollopeter, G., and Palmiter, R.D. (1996). Science 274, 1704-1707.

Farooqi, I.S., Yeo, G.S., Keogh, J.M., Aminian, S., Jebb, S.A., Butler, G., Cheetham, T., and O'Rahilly, S. (2000). J. Clin. Invest. 2, 271-279.

Felson, D.T., Zhang, Y., Hannan, M.T., and Anderson, J.J. (1993). J. Bone Miner. Res. 8, 567-573.

Friedman, J.M., and Halaas, J.L. (1998). Nature 395, 763-770.

Ghilardi, N., Ziegler, S., Wiestner, A., Stoffel, R., Heim, M.Il, and Skoda, R.C. (1996). Proc. Natl. Acad. Sci. U.S.A. 93, 6231-6235.

Halaas, J.L., Boozer, C., Blair-West, J., Fidahusein, N., Denton, D.A., and Friedman, J.M. (1997). Proc. Natl. Acad. Sci. U.S.A. 94, 8878-8883.

Huszar, D., Lynch, C.A., Fairchild-Huntress, V., Dunmore, J.H., Fang, Q., Berkemeier, L.R., Gu, W., Kesterson, R.A., Boston, B.A., Cone, R.D., Smith, F.J., Campfield, L.A., Burn, P., and Lee, F. (1997). Cell 1, 131-141.

Jochum, W., David, J.P., Elliott, C., Wutz, A., Plenk, H. Jr., Matsuo, K., and Wagner, E.F. (2000). Nature Med. 6, 980-984. 
Kappel, C.A., Bieberich, C.J., and Jay, G. (1994). FASEB J. 8, 583-592.

Karsenty, G. (1999). Genes Devel. 13, 3037-3051.

Kong, Y.Y., Yoshida, H., Sarosi, I., Tan, H.L., Timms, E., Capparelli, C., Morony, S., Oliveira-dosSantos, A.J., Van, G., Itie, A., Khoo, W., Wakeham, A., Dunstan, C.R., Lacey, D.L., Mak, T.W., Boyle, W.J., and Penninger, J.M. (1999). Nature 397, 315-323.

Kumar, T.R., Donehower, L.A., Bradley, A., and Matzuk, M.M. (1995). J. Intern. Med. 3, 233-238.

Laccy, D.L., Timms, E., Tan, I.L., Kelley, M.J., Dunstan, C.R., Burgess, T., Elliott, R., Colombero, A., Elliott, G., Scully, S., Hsu, H., Sullivan, J., Hawkins, N., Davy, E., Capparelli, C., Eli, A., Qian, Y.X., Kaufman, S., Sarosi, I., Shalhoub, V., Senaldi, G., Guo, J., Delaney, J., and Boyle, W.J. (1998). Cell 93, 165-176

Lee, G.H., Proenca, R., Montez, J.M., Carroll, K.M., Darvishzadeh, J.G., Lee, J.I., and Friedman, J.M. (1996). Nature 379, 632-635.

Levy, J.B., Schindler, C., Raz, R., Levy, D.E., Baron, R., and Horowitz, M.C. (1996). Endocrinology 137, 1159-1165.

Lu, D., Willard, D., Patel, I.R., Kadwell, S., Overton, L., Kost, T., Luther, M., Chen, W., Woychik, R.P., and Wilkison, W.O. (1994). Nature 371, 799-802.

Manolagas, S.C. (2000). Endocr. Rev. 2, 115-137.

Marcus, R., Feldman, D., and Kelsey, J. (1996). "Osteoporosis." Academic Press, San Diego.

Marsh, D.J., Hollopeter, G., Huszar, D., Laufer, R., Yagaloff, K.A., Fisher, S.L., Burn, P., and Palmiter, R.D. (1999). Nature Genet. 1, 119-122.

Moitra, J., Mason, M.M., Olive, M., Krylov, D., Gavrilova, O. Marcus-Samuels, B., Feigenbaum, L., Lee, E., Aoyama, T., Eckhaus, M., Reitman, M.L., and Vinson, C. (1998). Genes Devel. 12, 3168-3181.

Montague, C.T., Farooqi, I.S., Whitehead, J.P., Soos, M.A., Rau, H., Wareham, N.J, Sewter, C.P., Digby, J.E., Mohammed, S.N., Hurst, J.A., Cheetham, C.H., Earley, A.R., Barnett, A.H., Prins, J.B., and O'Rahilly, S. (1997). Nature 387, 903-908.

Nicholson, G.C., Moseley, J.M., Sexton, P.M., Mendelsohn, F.A., and Martin, T.J. (1986). J. Clin. Invest. 2, 355-360.

Parfitt, A.M., Drezner, M.K., Glorieux, F.H., Kanis, H.A., Malluche, H., Meunier, P.J., Ott, S.M., and Recker, R.R. (1987). J. Bone Miner. Res. 6, 595-610.

Poli, V., Balena, R., Fattori, E., Markatos, A., Yamamoto, M., Tanaka, H., Ciliberto, G., Rodan, G.A., and Costantini, F. (1994). EMBO J. 5, $1189-1196$.

Potts, J.T., and Juppner, H. (1998). "Parathyroid Hormone and Parathyroid Hormone-related Peptide in Calcium Homeostasis, Bone Metabolism, and Bone Development: the Proteins, Their Genes, and Receptors." Academic Press, San Diego.

Raven, P., Cizza, G., Bjarnason, N.H., Thompson, D., Daley, M., Wasnich, R.D., McClung, M., Hosking, D., Yates. A.J., and Christiansen, C. (1999). J. Bone Miner. Res. 14, 1622-1627.

Reid, I.R. (1997). N. Engl. J. Med. 337, 420-421.

Riggs, B., and Khosla, S. III. (1998). J. Bone Miner. Res. 13, 763-773.

Riggs, B.L., and Melton, L.J. (1986). N. Engl. J. Med. 314, 1676-1686.

Schwartz, M.W., Erickson, J.C., Baskin, D.G., and Palmiter, R.D. (1998). Endocrinology 5, 2629-2635.

Simonet, W.S., Lacey, D.L., Dunstan, C.R., Kelley, M., Chang, M.S., Lithy, R., Nguyen, H.Q., Wooden, S., Bennett, L., Boone, T., Shimamoto, G., DeRose, M., Elliott, R., Colombero, A., Tan, H.L., Trail, G., Sullivan, J., Davy, E., Bucay, N., Renshaw-Gegg, L., Hughes, T.M., Hill, D., Pattison, W., Campbell, P., and Boyle, W.J. (1997). Cell 89, 309-319.

Spiegelman, B.M., and Flier, J.S. (1996). Cell 87, 377-389.

Strobel, A., Issad,T., Camoin, L., Ozata, M., and Strosberg, A.D. (1998). Nature Genet. 3, 213-215.

Tartaglia, L.A., Dembski,M., Weng, X., Deng, N., Culpepper, J., Devos, R., Richards, G.J., Campfield, L.A., Clark, F.T., Deeds, J., Muir, C., Sanker, S., Moriarty, A., Moore, K.J., Smutko, J.S., Mays, G.G., Woolf, E.A., Monroe, C.A., and Tepper, R.I. (1995). Cell 83, 1263-1271. 
Thomas, T., Gori, F., Khosla, S., Jensen, M.D., Burguera, B., and Riggs, B.L. (1999). Endocrinology 140, 1630-1638.

Tremollieres, F.A., Pouilles, J.M., and Ribot. C. (1993). J. Clin. Endocrinol. Metab. 77, 683-686.

Vaisse, C., Halaas, J.L., Horvath, C.M., Darnell, J.E.J., Stoffel, M., and Friedman, J.M. (1996). Nature Genet. 14, 95-97.

Westvik, J. (1996). Acta Paediatr. Suppl. 413, 44-51.

Zhang, Y., Proenca, R., Maffei, M., Barone, M., Leopold, L., and Friedman, J.M. (1994). Nature 372, 425-432. 
